\title{
Erratum to: Investigation into the selective laser sintering of styrene-acrylonitrile copolymer and postprocessing
}

\author{
Chunze Yan • Yusheng Shi $\cdot$ Jingsong Yang $\cdot$ Jinhui Liu
}

Published online: 6 July 2010

(C) Springer-Verlag London Limited 2010

Erratum to: Int J Adv Manuf Technol

DOI 10.1007/s00170-010-2681-8

Unfortunately, the authors have included Figure 13 by mistake. Please ignore this figure.

The online version of the original article can be found at http://dx.doi. org/10.1007/s00170-010-2681-8.

C. Yan $(\bowtie)$

College of Material Science and Chemical Engineering,

China University of Geosciences (Wuhan),

Wuhan 430074, Hubei, China

e-mail: Yesoar@gmail.com

Y. Shi $\cdot$ J. Yang $\cdot$ J. Liu

State Key Laboratory of Material Processing and Die and Mould

Technology, Huazhong University of Science and Technology,

Wuhan 430074, Hubei, China 